\title{
COVID-19 y la atención de las y los niños en el consultorio de medicina general
}

\author{
COVID-19 and the attention of children in the general medicine clinic
}

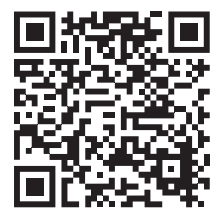

José Alfonso Maya Barrios*

\section{RESUMEN}

La población pediátrica, aunque en menor medida, también se ha visto afectada por el COVID-19, a continuación, se presentan seis puntos principales para los médicos que se encuentran en la primera línea de batalla con esta población. El primer punto se enfoca en la atención del niño y la niña en el consultorio médico y la evaluación del médico pediatra, el segundo de ellos las presentaciones clínicas de la enfermedad más frecuentes en esta población, el tercero, sobre las características presentes en paciente grave y crítico con COVID-19, el cuarto, del síndrome inflamatorio multisistémico asociado al virus SARS-CoV-2, el quinto punto son las consideraciones estacionales junto con la coexistencia entre virus SARS-CoV-2 e influenza y por último la presentación de casos clínicos de pacientes contagiados por el virus. Es importante prestar cuidado a los puntos de enfoque para brindar un manejo adecuado al paciente pediátrico en el primer nivel de atención.

Palabras clave: COVID-19, primer nivel de atención, población pediátrica

\begin{abstract}
The pediatric population, although to a lesser extent it has also been affected by COVID-19, below are six main points for doctors who are on the front line of battle with this population. The first point focuses on the care of the child in the doctor's office and the evaluation of the pediatrician, the second of them the most frequent clinical presentations of the disease in this population, the third, on the characteristics present in seriously ill patients and critical with COVID-19, the fourth, of the multisystemic inflammatory syndrome associated with the SARS-CoV-2 virus, the fifth point is the seasonal considerations together with the coexistence between the SARS-CoV-2 virus and influenza and finally the presentation of cases clinics of patients infected with the virus. It is important to pay attention to the focus points to provide adequate management to the pediatric patient at the first level of care.
\end{abstract}

Keywords: COVID-19, first level of care, pediatric population
* Médico Pediatra. Hospital General «Dr. Manuel Gea González»

Correspondencia: JAMB, jamayab@ hotmail.com Conflicto de intereses: Ninguno.

Citar como:

Maya BJA. COVID-19 y

la atención de las y los niños en el consultorio de medicina general. Rev CONAMED. 2020; 25(supl. 1): s31-s40. https://dx.doi. org/10.35366/97346

Financiamiento:

Ninguno.

Recibido: 04/12/2020. Aceptado: 04/12/2020 
Para mí es un placer y un gusto poder compartir una presentación que, desde mi punto de vista, debe ser bastante enriquecedora para los médicos del primer nivel de atención, sobre todo porque hay muchas dudas acerca de lo que pasa con COVID-19 en los niños y en las niñas, y esta presentación precisamente va dirigida para esos médicos que están en la primera línea de batalla y que posiblemente vayan a tener que enfrentarse a cuadros de esta índole.

El contenido de la plática está dividido en seis secciones. La primera de ellas se enfoca en la atención del niño y de la niña en el consultorio médico, partiendo de los objetivos e importancia de la evaluación del paciente pediátrico en el primer nivel de atención. La segunda sección habla de la presentación clínica que con mayor frecuencia se ha documentado de COVID-19 en el paciente pediátrico. La tercera sección trata de las características que se han asociado con COVID-19 grave y crítico en el paciente pediátrico, ya que una proporción muy baja de pacientes desarrollan esta complicación y hay algunas características que se han asociado con ello. La cuarta parte es algo muy interesante que se ha publicado en los pacientes pediátricos con COVID-19 y es la presencia del síndrome inflamatorio multisistémico, asociado precisamente al virus SARS-CoV-2. La quinta parte son las consideraciones estacionales que cualquier profesional de la salud debe tomar en cuenta cuando el virus SARS-CoV-2 comience a coexistir con el virus de la influenza. Finalmente, la sexta parte es una integración de dos casos clínicos para reafirmar los conceptos previamente presentados y conclusiones del tema.

\section{ATENCIÓN DEL NIÑO Y LA NIÑA EN EL PRIMER NIVEL DE ATENCIÓN}

En México, como en muchos países de Latinoamérica y algunos de Europa, en el primer nivel de atención se delega a los médicos generales la atención del paciente pediátrico. Pocos países tienen un médico pediatra que se encargue de hacer esta atención. El médico de primer contacto debe conocer los objetivos que se buscan al atender a un niño en el consultorio. Estos pueden dividirse en los siguientes:
1. La promoción de la salud debe ser el objetivo principal de la atención del niño y la niña en el primer nivel de salud. El fin de la promoción de la salud es limitar y prevenir la presentación de enfermedades. Esta recomendación ha sido documentada en guías de práctica clínica de México y en la Norma Oficial Mexicana. (Control y seguimiento de la nutrición, el crecimiento y desarrollo de la niña y del niño menor de cinco años. México: Secretaría de Salud; 02 de diciembre de 2015).

2. La detección oportuna de enfermedades crónicas, subagudas o agudas, incluyendo datos de alarma para asegurar una atención integral del paciente de alta calidad.

3. Garantizar una atención integral cuando el límite de la atención en el primer nivel se ha alcanzado, es decir, asegurar que el paciente pueda ser referido a un centro de Segundo o Tercer Nivel en donde reciba los cuidados correspondientes con su patología.

Cuando consideramos objetivos secundarios del médico general se pueden incluir en la promoción de la salud todas las acciones dirigidas a mejorar las conductas de nutrición y de actividad física. Al hacerlo, se busca una mitigación en la presentación de enfermedades crónicas del paciente pediátrico. México es uno de los primeros países en obesidad infantil y tiene que ver con los hábitos de alimentación y la falta de actividad física. Al final del día, el médico como promotor de la salud y educador en salud debe ser el promotor principal de cambios en hábitos y conductas asociadas con estas enfermedades. Estas entidades crónicas lamentablemente han sido determinantes en la mortalidad de los pacientes con COVID-19 en los adultos.

El segundo objetivo es la revisión del crecimiento y desarrollo, así como inmunizaciones. La vacunación tiene un papel importante en el contexto de COVID-19, no por la existencia de una vacuna contra SARS-CoV-2, ya que hasta el día de hoy no contamos con ella, sino por las vacunas que deben aplicarse en todos los niños que previenen muchas enfermedades que pueden competir en el mismo niño, principalmente hablamos del virus de la influenza, uno de los más importantes en la temporada invernal. Se debe estar atento en revisar 
la cartilla nacional de vacunación en todo paciente que se atienda en consulta.

Otro objetivo secundario es identificar los factores de riesgo y correlacionarlo con datos de alarma, por ejemplo, si tengo un niño que padece un síndrome congénito o alguna enfermedad crónica, podría hacer que la presentación de COVID-19 sea mucho más grave que en un paciente sin comorbilidades.

Por último, tomemos en cuenta cuándo referir oportunamente. Si un paciente tiene datos de alarma y busca atención en un Primer Nivel, es prioritario referirlo a una institución de Segundo o Tercer Nivel que mejor convenga al paciente.

Por otro lado, se debe particularizar la atención de los distintos grupos de edad, por ejemplo, en un paciente de un mes de vida en donde sabemos que los datos de dificultad respiratoria y respuesta inflamatoria sistémica van a ser mucho más evidentes en la exploración y la sintomatología dependerá completamente de lo que los padres o cuidadores del paciente se hayan dado cuenta. En este sentido, el médico general debe estar familiarizado con los lactantes, preescolares, escolares y adolescentes y enfocarse en tres aspectos de la historia clínica:

1. Los antecedentes personales: todo lo relacionado con el estado de salud previo al motivo de la consulta actual del paciente.

2. El cuadro clínico: interrogar minuciosamente la presentación de los síntomas y en el contexto de COVID-19, con base en la evidencia publicada, conocer los síntomas que pueden integrar esta enfermedad.

3. Los hallazgos que se van a buscar intencionadamente en la exploración física.

Los antecedentes personales que se deben indagar son los factores genéticos, enfermedades congénitas o algunos síndromes que pudieran estar presentes en el niño y que por sí mismos van a hacer que cualquier enfermedad infecciosa pudiera tener una presentación mucho más grave y COVID-19 no es la excepción. Los factores ambientales naturalmente pueden tener influencia, ya que si el niño o la niña viven en un entorno contaminado o el ambiente social es inadecuado por la presencia de hacinamiento o pobreza pueden relacionarse con un desenlace mucho más grave.
Otra característica a revisar son las enfermedades que el paciente pudiera tener, por ejemplo, alergias, asma, cardiopatías, trasplantes previos, neoplasias, presencia de quimio o radioterapia.

No hay evidencia clara de que la lactancia materna proteja contra COVID-19; sin embargo, con base en el conocimiento que tenemos de la prevención de otras enfermedades infecciosas como son neumonía, bronquiolitis o gastroenteritis, podríamos considerar que es muy probable que la lactancia materna juegue un papel protector de las infecciones por SARS-CoV-2.

Como se mencionaba con anterioridad, no tenemos una vacuna aprobada en contra de COVID-19, pero sí tenemos vacunas que nos pueden proteger de otras enfermedades que pudieran coexistir con COVID-19. El contacto con personas enfermas es un dato que se debe indagar intencionadamente, para saber si en los últimos 10 o 14 días ese niño ha estado expuesto no nada más a un enfermo por COVID-19, sino a un entorno que podría haber estado contaminado por una persona con COVID-19.

Al averiguar el cuadro clínico se debe hacer hincapié en describir el tipo de inicio de los síntomas del niño, recordemos que SARS-CoV-2 entra en el organismo del paciente pediátrico y no es una presentación subaguda o atípica, sino que tiene una presentación aguda muy súbita con una claridad de síntomas; aunque el espectro de la enfermedad es muy amplio, muchas veces se presenta con síntomas pivote. La relación causal del contacto con pacientes con COVID-19 o entorno de riesgo hasta 10 a 14 días antes de la presentación de síntomas puede estar asociados con esta enfermedad.

COVID-19 en el niño puede tener un espectro de presentación que puede ir desde una forma asintomática o leve con prueba PCR en tiempo real positivo para SARS-CoV-2, hasta la presencia de un cuadro moderado, grave o incluso crítico. Indagar cuáles de los síntomas están asociados con cada una de las categorías nos dará una mejor estadificación del riesgo de los pacientes.

La exploración física de un niño con sospecha de COVID-19 deberá ir dirigida a determinar si este paciente lo podemos atender en el Primer Nivel de atención o lo debemos referir oportunamente a un Segundo o Tercer Nivel.

La mayoría de las veces un niño que puede llegar a tener datos de gravedad respiratoria es porque 
tiene neumonía, eso es lo que con mayor frecuencia define a los pacientes con COVID-19 grave. Se va a manifestar clínicamente en el paciente pediátrico no sólo con síntomas respiratorios, sino también con alteración en la frecuencia respiratoria. Los valores de corte que ha manejado la OMS para considerar a un niño con polipnea son: < 1 mes no debe respirar nunca > 70 respiraciones por minuto; de un mes a 12 meses de edad no debe rebasar 60 respiraciones por minuto; de uno a dos años el límite es de 50 respiraciones por minuto; de dos a cinco años 40 respiraciones por minuto y un niño > 5 años no debe de respirar $>30$ veces por minuto; si presentara ese dato clínico, entonces puede ser un parámetro que nos pueda diferenciar al paciente que podemos manejar dentro de la unidad de Primer Nivel o que requiera atención en un hospital de Segundo o Tercer Nivel.

Otros de los datos de dificultad respiratoria son aquellos que traducen un aumento del trabajo respiratorio del paciente y que se caracteriza por quejido respiratorio en el paciente que es muy pequeño, disociación toracoabdominal, tiraje intercostal y retracción xifoidea son datos que se pueden observar desde el momento en que se descubre al paciente.

En la auscultación de los campos pulmonares se puede explorar intencionadamente la presencia de datos clínicos que nos integren una infección de vías respiratorias inferiores; éstos pueden ser estertores crepitantes, estertores roncantes y/o sibilancias, y que a su vez no pueden orientar a qué nivel de la vía respiratoria inferior está el daño por este virus.

Cuando tenemos un paciente con una infección respiratoria que entra a nuestro consultorio, contamos con herramientas que podríamos utilizar para saber qué tan grave es el cuadro. Una de las herramientas que mejor utilidad tiene es el oxímetro de pulso.

El oxímetro nos da una evaluación del nivel de saturación de oxígeno a nivel periférico en la sangre del paciente, nos traduce si está teniendo un deterioro a nivel pulmonar. El valor de corte que se ha sugerido para considerar un dato de gravedad es del 92\% a oxígeno ambiental ( $\left.\mathrm{FiO}_{2} 21 \%\right)$. En ocasiones, existe la posibilidad de que los niños llegan a tener neumonía y no tiene un aumento del trabajo respiratorio, estos pacientes pueden beneficiarse del uso sistemático del oxímetro de pulso, ya que pueden tener alteraciones detectadas tempranamente.

El uso de escalas de evaluación de gravedad respiratoria ha sido publicado en trabajos de investigación, incluyendo revisiones sistemáticas. Algunas escalas han sido validadas para pacientes con bronquiolitis o asma. Lo que tienen en común las escalas de valoración de gravedad es que toman todos los datos clínicos de gravedad respiratoria y lo categorizan por medio de una asignación de puntos para darnos una estadificación del paciente en un estado leve, moderado o severo. Ejemplo de estas escalas son: Wood-Downes-Ferrés, Score Pulmonary Respiratory Distress Index.

Por otro lado, tenemos herramientas que carecen de utilidad en el Primer Nivel de atención, por ejemplo, los estudios del laboratorio y gabinete. Si tenemos un paciente con sospecha de COVID-19 leve no se deben utilizar recursos en realizar estudios de laboratorio, ya que no van a modificar la conducta con el paciente; la detección de SARS-CoV-2 por medio de la PCR en tiempo real tampoco es un estudio que modifique el tratamiento a seguir en los casos leves; por lo tanto, si se tiene un paciente que ha sido evaluado y categorizado como sospecha de COVID-19 leve, no se justifica la indicación de más estudios paraclínicos, ya que el tratamiento, seguimiento y las medidas de contención tampoco van a cambiar; por ende, es mejor considerar a este paciente como una enfermedad respiratoria viral y no utilizar un recurso que seguramente un paciente moderado, grave o crítico necesitará. La radiografía del tórax o la tomografía de tórax tampoco son de utilidad en el contexto del médico de primer contacto. Hay que recordar que la categorización del estado de gravedad del paciente con COVID-19 debe hacerse esencialmente con el examen clínico y no por los estudios paraclínicos.

\section{PRESENTACIÓN CLÍNICA DE COVID-19 EN EL PACIENTE PEDIÁTRICO}

Con respecto a la presentación de COVID-19 en el paciente pediátrico se han postulado diversas teorías alrededor de la menor gravedad con respecto a los de edad avanzada; esto puede tener diferentes explicaciones, aunque todo lo que se ha mencionado hasta ahora en la literatura son hipótesis. El primero es que posiblemente la exposición 
más alta a otros patógenos respiratorios o de vía de entrada respiratoria en el niño podría competir con el virus SARS-CoV-2 y atenuar la entrada de los virus. Usualmente en el ambiente de la población en edad escolar o preescolar, que asiste a la guardería, estancia infantil, el kínder o la primaria y tiene muchos compañeros que presentan enfermedades respiratorias, compiten al mismo tiempo muchos virus y hace que algunos niños ya no se enfermen tanto; entonces esta competencia con otros patógenos podría estar involucrada en la menor presentación de COVID-19 en los niños.

La segunda teoría es que sabemos que el sistema inmunológico de los niños está en un proceso de maduración, por ende, al momento en el que entra el virus SARS-CoV-2 no desencadena una respuesta inmunológica tan severa en donde se encuentra involucrada la cascada de citocinas relacionada con la presentación grave de COVID-19, esto hace que el niño no manifieste con tanta gravedad esta enfermedad.

La tercera teoría es la menor actividad del receptor de Enzima Convertidora Angiotensina II, el niño tiene menos receptores; éstos se han asociado con la vía de entrada del virus SARS-CoV-2 hacia las células, sobre todo las células del pulmón y las de las células involucradas con el sistema circulatorio. Esta menor actividad de los receptores puede romper una vía de entrada eficaz para el virus disminuyendo la respuesta y replicación del virus dentro del huésped.

La última es que a raíz del confinamiento que nosotros tenemos por la pandemia de COVID-19 hay mayor resguardo en casa, y los que están más resguardados en casa son los niños, ellos han tenido una menor exposición a patógenos respiratorios y, por lo tanto, hay menos casos de COVID-19.

Acerca de la presentación de COVID-19 en pacientes pediátricos, hay diversos trabajos, incluyendo revisiones sistemáticas, que suman evidencia importante que nos ayuda a conocer el cuadro clínico que pudiera presentar un paciente pediátrico, en ese sentido, encontramos con que todas coinciden en cuatro datos clínicos que pueden estar presentes en el niño con infección por SARS-CoV-2:

Primero, la fiebre es el dato pivote. Frecuentemente, este dato es el centinela para la sospecha de la enfermedad y puede estar acompañada de datos que aparecen posteriormente. Estos datos pueden ser tos seca, irritabilidad o fatiga y en los casos que se han considerado graves o críticos: dificultad respiratoria. Uno de los puntos a considerar es la existencia de niños con neumonía sin dificultad respiratoria franca, ahí es donde tenemos que afinar muy bien los sentidos clínicos para poder discernir entre un niño que pudiera deteriorarse y un niño que no.

El espectro de la enfermedad, como se ha mencionado antes, abarca desde el niño sintomático, que se define como un paciente que tiene un estudio PCR positivo para SARS-CoV-2, pero que no tiene ningún síntoma. Estos niños habitualmente se han detectado por el estudio epidemiológico al ser contactos directos de casos, normalmente familiares directos. En el seguimiento de esos mismos niños no presentan sintomatología; sin embargo, si hay confirmación diagnóstica por medio del estudio de RT-PCR.

Se estima que entre 30 y 35\% de los niños se comporta de una manera asintomática y otro 35 hasta $40 \%$ de forma leve; sin embargo, hay algunos estudios que, sumando las dos presentaciones, señalan que esta proporción podría ser incluso cercana a 90\%. Además, la presentación de infecciones respiratorias en el niño por otros virus como el rinovirus, el virus sincicial respiratorio, el virus parainfluenza, responsables todos de un cuadro clínico con tos, fiebre, rinorrea, conjuntivitis, datos prácticamente indistinguibles de COVID-19. En resumen, en una proporción muy alta de niños, las infecciones respiratorias por los virus estacionales son indiferenciables de las infecciones por SARS-CoV-2.

COVID-19 tiene una intensidad moderada que se estima entre 3 y 5\% de los niños. Lo que define la presencia de este estadio es la presencia de neumonía, aunque es posible que no existan datos clínicos de gravedad; es decir, la oximetría estará alterada o en la clasificación de gravedad respiratoria va a estar en un estadio moderado, y al realizar un estudio de imagen indicado en estos pacientes encontraremos datos compatibles con neumonía. A partir de la intensidad moderada, los pacientes deben manejarse intrahospitalariamente. En este sentido, son niños que no deberían ser atendidos en el primer nivel de atención más que para valoración inicial para una posterior referencia a un Segundo o Tercer Nivel.

El paciente con COVID-19 grave es aquel que ya con evidencia de neumonía tiene un aumento 
del trabajo respiratorio, manifestando datos de dificultad respiratoria muy evidentes. Fisiopatológicamente esto se relaciona con una mayor proporción de tejido pulmonar afectado por el virus SARS-CoV-2. EI COVID-19 crítico presenta falla orgánica múltiple que no involucra solamente daño pulmonar, sino falla en la coagulación, repercusión renal y un mayor riesgo de desenlace fatal.

El 24 de agosto de 2020, la Secretaría de Salud, por medio de un comunicado de la Dirección General de Epidemiología, publicó la definición operacional del caso sospechoso de enfermedad respiratoria viral, que incluiría aquellos con sospecha de COVID-19, esto con el objetivo de que en la temporada invernal no todos los casos que tengan tos, fiebre y dificultad respiratoria se cataloguen como COVID-19, ya que el virus SARS-CoV-2 no será el único agente etiológico asociado con estos cuadros infecciosos. En el contexto del niño, sabemos que el virus sincicial respiratorio a partir de los meses de octubre y noviembre es uno de los principales implicados en la presentación de infecciones respiratorias inferiores como son bronquiolitis. Del mismo modo, la influenza es uno de los principales agentes etiológicos responsables de neumonías en pacientes pediátricos en la temporada invernal.

Por lo tanto, la definición operacional incluye criterios mayores como pueden ser tos, fiebre y disnea como dato de gravedad, o cefalea, y ésta en los menores de cinco años puede ser sustituida por irritabilidad, más, al menos, uno de los criterios menores como son mialgias, artralgias, odinofagia, escalofríos, dolor torácico, rinorrea y recientemente se introdujo anosmia, disgeusia y conjuntivitis; si tenemos un paciente que cumple con esta definición operacional, podemos decir que es un caso de sospecha de COVID-19, pero de igual manera podría ser influenza o virus sincicial respiratorio.

Después de recibir y revisar a un paciente pediátrico se deben tomar en cuenta los datos de gravedad que pudieran asociarse con COVID-19 moderado, grave o crítico. Éstos pueden agruparse de la siguiente manera:

1. Datos de dificultad respiratoria: cualquier niño que tenga tiraje intercostal, retracción xifoidea, aumento del trabajo respiratorio, quejido respiratorio, hasta dolor pleural en un niño queya puede manifestarlo verbalmente es un dato de alarma.
2. Polipnea: se ha mencionado con anterioridad los valores corte de la frecuencia respiratoria, dependiendo en la edad del niño y si es menor de un mes, debemos conocer que $>70$ veces por minuto se considera un dato de alerta.

3. La oximetría de pulso < $92 \%$, la cual debe corroborarse dos a tres veces y si esto es consistente hay que considerar referir al paciente para una atención especializada.

4. Incapacidad o dificultad para alimentarse: si un paciente no puede alimentarse o es un lactante que no recibe alimento y está deshidratado 0 letárgico o que incluso ha llegado a convulsionar, debe ser referido a un hospital.

Las guías de tratamiento para COVID-19 en niños han sido muy enfáticas en señalar que la mayoría de los pacientes pediátricos con COVID-19 son pacientes categorizados como leves, por lo mismo, no van a requerir más allá de un manejo sintomático. El aislamiento social en un paciente que tiene COVID-19 leve es fundamental para que no haya diseminación de este mismo virus y debe considerarse entre 10 y 14 días. El tratamiento debe ser sintomático, y en los casos considerados como moderados, graves o críticos el manejo se va a basar en el soporte ventilatorio, soporte hemodinámico y en la evaluación multisistémica del paciente.

Ningún tratamiento antiviral o coadyuvante ha sido aprobado, incluso no han sido estudiado en niños todos los tratamientos antivirales ni todos los tratamientos que se han postulado para el paciente adulto con COVID-19. No existen hasta la fecha ensayos clínicos controlados en pacientes pediátricos, esto responde sobre todo a la baja frecuencia de la presentación COVID-19 grave y crítico en la población pediátrica. En resumen, a la fecha no hay publicaciones que nos hablen de un tratamiento que se deba recomendar en los niños, ya no digamos para un paciente grave, sino tampoco para un paciente leve y mucho menos para prevenir la infección por el virus SARS-CoV-2.

\section{CARACTERÍSTICAS DE LOS NIÑOS CON COVID-19 GRAVE}

Las características de los niños que tienen COVID-19 han sido estudiadas en diferentes series de 
casos y revisiones sistemáticas. Se ha concluido que el sexo masculino es uno de los factores de riesgo que se asocia con mayor gravedad, teniendo una proporción de 70 a 76\% en los casos más graves y disminuyendo en los casos leves y moderados en donde la relación hombre-mujer tiende más a la igualdad.

Otro de los datos asociados con gravedad es el inicio del cuadro clínico con síntomas respiratorios graves, ya que se ha asociado que estos pacientes con mayor frecuencia requieren atención especializada en un Segundo o en un Tercer Nivel y necesitarán soporte mecánico ventilatorio. Contrario a lo que se ha descrito en adultos, 38 y $40 \%$ de los pacientes pediátricos graves necesitan apoyo mecánico ventilatorio, y a pesar de ello, la supervivencia en los niños es significativamente más alta que en los adultos, así la mayoría de los pacientes resuelven el proceso inflamatorio respiratorio y se extuba de manera satisfactoria.

Las comorbilidades médicas complejas que acompañan a pacientes con COVID-19 grave se han encontrado en más de $80 \%$ de este grupo de niños, con particular relevancia está la obesidad infantil. El médico de primer contacto debe saber que debe ser promotor de la salud. Cuando esta promoción no es eficiente, se traduce en una mayor proporción de pacientes con obesidad infantil, por lo tanto, los pacientes con obesidad infantil pueden ser vulnerables a presentar COVID-19 grave. Se debe cuidar mucho esa parte y tomar cartas en el asunto para que los pacientes con obesidad infantil se recuperen y cuando tengan un regreso a la nueva normalidad no se incluyan en el grupo más vulnerable. Por otro lado, la diabetes, neoplasias, exposición a quimioterapia, enfermedades congénitas, cardiopatías congénitas, trisomía 21, entre otras, se han relacionado con la presencia de COVID-19 grave.

\section{SÍNDROME INFLAMATORIO MULTISISTÉMICO ASOCIADO CON SARS-COV-2}

El síndrome inflamatorio multisistémico que se ha asociado con SARS-CoV-2 no es una enfermedad frecuente, pero es una enfermedad que ha despertado mucha inquietud, sobre todo en los que están relacionados con la población pediátrica.
A partir de un trabajo que se publicó en The Lancet en el mes de marzo de 2020, las autoridades de salud del Reino Unido se dieron cuenta de que con el incremento de casos de COVID-19 en su país aumentó la demanda de servicios de salud de niños con síndrome inflamatorio multisistémico, el cual es una enfermedad muy parecida a la enfermedad de Kawasaki, que se caracteriza por conjuntivitis bulbar o hiperemia conjuntival, exantema polimorfo, lengua en fresa, descamación o enrojecimiento de las palmas y de las plantas, y lo más grave que presentan estos pacientes son alteraciones cardiológicas que se pueden asociar con aneurismas a nivel de las arterias coronarias o ataques cardiacos en los niños afectados.

La importancia de detectar oportunamente un síndrome inflamatorio multisistémico radica en que el manejo se debe realizar en un hospital de Segundo o Tercer Nivel. El tratamiento de estos pacientes no es ambulatorio, por lo mismo, cualquier caso con sospecha de enfermedad de Kawasaki o que tuviera alguna característica asociada con el síndrome inflamatorio multisistémico debe referirse inmediatamente. Tomando en cuenta la evidencia publicada en revisiones sistemáticas acerca de este tema, se observa que la edad media de presentación es un poco mayor que en la enfermedad de Kawasaki, la cual tiene un promedio de presentación entre los tres y cinco años, en contraste con los 7.3 a 10 años del síndrome inflamatorio multisistémico. Por otro lado, el sexo masculino sigue siendo el más predominante, con 59\%. Las manifestaciones gastrointestinales forman parte del $87 \%$ de los casos, 73\% tienen manifestaciones mucocutáneas y 70\% van a tener alteraciones cardiovasculares; por ello, la importancia de la detección oportuna, porque algunos casos pueden tener repercusión hemodinámica que podría requerir manejo en la Unidad de Terapia Intensiva pediátrica.

En conclusión, la definición de este síndrome implica a un paciente que tenga fiebre, alteraciones inflamatorias por laboratorio y además evidencia clínica de enfermedad grave que requiera hospitalización con la afectación multiorgánica, más una reciente o actual infección por SARSCoV-2 o una exposición a casos de COVID-19 sin un diagnóstico alternativo, siendo muy claro que en el virus SARS-CoV-2 la presentación de COVID-19 no 
es igual a un síndrome inflamatorio multisistémico, pero este virus puede llegar a tener la capacidad de desencadenar la cascada de inflamación en el niño y que de una a tres semanas después presente síndrome inflamatorio multisistémico, por eso es la importancia de que si un niño tiene COVID-19 leve, nosotros hagamos énfasis en darle un seguimiento para estar seguros que no presente ninguno de estos datos. Si se atendiera un paciente pediátrico con datos clínicos del síndrome inflamatorio multisistémico, se debe preguntar intencionadamente si ha tenido datos en la definición operacional de enfermedad respiratoria viral.

\section{CONSIDERACIONES ESTACIONALES}

El virus de la influenza año con año tiene un comportamiento estacional con mayor presentación en el hemisferio norte entre los meses de octubre y febrero. A partir de la semana epidemiológica 48 comienza a haber un incremento de la demanda de consultas en el primer nivel de atención por enfermedad similar a influenza, que en la definición operacional actual llamaremos enfermedad respiratoria viral, por lo tanto, como cada año se espera que la demanda de consulta por enfermedad respiratoria viral aumente hasta cuatro veces más que el resto del año.

A partir de diciembre, existe el riesgo de que haya mayor número de contagios y que al consultorio del médico de primer contacto aumenten los casos de sospecha por COVID-19, pero esto probablemente va a ser responsabilidad de otros agentes. Lo más importante deberá ser catalogar adecuadamente la gravedad del paciente para referir oportunamente los casos que así lo requieran.

Asimismo, en estas últimas temporadas la mortalidad en los niños por neumonía asociada a influenza aumenta en las últimas y en las primeras semanas del año, en este sentido, se estima que pudiera haber un pico de mortalidad secundario a infecciones respiratorias bajas, que incluirá neumonía, bronquiolitis, laringotraqueitis y que no todas serán atribuibles al virus SARS-CoV-2.

No hay estrategia más efectiva para evitar la morbimortalidad del virus de influenza que la vacunación; ahora con mayor fortaleza debemos defender la vacuna de la influenza en los menores de cinco años, la cual se aplica a partir de los seis meses de edad, para evitar la presentación de neumonías que año con año ocupan las terapias intensivas y los servicios de pediatría de nuestro sector salud.

\section{ESCENARIOS CLIINICOS Y CONCLUSIONES}

Para integrar y concluir, se han puesto dos escenarios clínicos que muy probablemente los médicos generales, médicos de primer contacto, incluso pediatras, estaremos viendo diariamente en nuestro consultorio.

El primer caso es un masculino de siete años, tiene sus abuelos paternos que viven en su domicilio y que han sido hospitalizados por neumonía secundaria a COVID-19. El papá no acude a revisión, pero tuvo un cuadro de fiebre que remitió hace una semana, la mamá es asintomática. El niño no tiene antecedentes personales de importancia, niega comorbilidades y las inmunizaciones están completas de acuerdo con la edad.

El motivo de consulta es por preocupación de la mamá por el contacto familiar con COVID-19. Esto es algo que se está repitiendo día a día en el Primer Nivel de atención: el niño o la niña no tienen ningún síntoma, pero acaban de informarle al abuelo, tío, familiar con el cual tuvieron contacto hace unos días, que tiene COVID-19 o que falleció por COVID-19.

A la exploración física tenemos un escolar con un peso y talla normal, con los siguientes signos vitales: frecuencia cardiaca 80 por minuto, frecuencia respiratoria de 26 por minuto (es decir, no rebasa el valor corte que nosotros tenemos en los niños mayores de siete años que es de 30 por minuto), temperatura axilar 36.4, y la oximetría de pulso está en 96\%, no hay datos patológicos en la exploración.

Tenemos un niño que aparentemente está sano y lo único relevante y por lo cual está ocupando un espacio en la agenda del médico es preocupación familiar. Las preguntas a plantear: ¿está indicado realizar algún estudio en este paciente?, la mamá es muy clara y quiere que le hagan la prueba de detección de COVID-19 porque el niño muy posiblemente lo tenga; la respuesta es no, un paciente que no tiene datos clínicos de enfermedad 
respiratoria viral, aunque haya tenido un contacto cercano, no debe utilizar este recurso para realizar una prueba de detección, porque muchos de los niños van a cursar asintomáticos o muchos de los niños van a tener un cuadro leve de COVID-19.

¿Amerita algún tratamiento actualmente disponible? Como se he mencionado antes, no hay ningún tratamiento que sea profiláctico para ayudar al niño a que no presente las manifestaciones clínicas de COVID-19; la vitamina C, la azitromicina y algunos otros fármacos, no tienen evidencia científica en niños como para utilizarse de manera segura y eficaz para evitar la presentación de COVID-19.

Por último, ¿qué recomendaciones le darían a él y a su familia? Ya que no tiene indicada una prueba de detección y no se le indicará un tratamiento específico contra COVID-19, lo más importante sería guardar la sana distancia. El confinamiento en casa de 10 a 14 días en paciente sintomático. En este caso, el niño no tiene ningún síntoma, debe guardar su distancia y guardar el confinamiento para evitar que pudiera contagiarse en caso de que no esté enfermo.

Además, hay que vigilar los síntomas, si este paciente presenta fiebre, dificultad respiratoria, debe tener una consulta médica oportuna para que se valore y catalogue adecuadamente en COVID-19 grave, moderado o leve.

El siguiente caso clínico es un paciente femenino de 18 meses de edad, la paciente ha estado en aislamiento, afirman que no han salido de casa y que han guardado el confinamiento gracias a que pueden trabajar en casa. No recibió seno materno y sus vacunas están completas hasta el año.

El motivo de la consulta inició hace tres días, cuando la paciente empezó con tos seca que ha ido incrementando en intensidad y en frecuencia; además, esta tos ha sido rubicundizante, disneizante y emetizante, se integra al cuadro clínico fiebre desde hace ocho horas llegando hace 38.5 grados y ha tenido dificultad para respirar desde hace tres horas, motivo por el cual la mamá decide llevarla a la consulta médica de primer contacto.

A la exploración encontramos una lactante con peso y talla normal, la frecuencia es de 140 por minuto, la frecuencia respiratoria está en 55 respiraciones por minuto, es una frecuencia respiratoria que ya rebasó los límites por edad, es decir, ya tenemos un dato de alerta, en la temperatura axilar 38.4 grados centígrados y la oximetría de pulso que hemos medido es de $88 \%$, otro dato de alerta. Tenemos dos datos de alarma hasta este momento. Está irritable, su tórax tiene retracción xifoidea y tiene tiraje intercostal bajo, dos datos de alerta más; aumentó el trabajo respiratorio y a la auscultación de los campos pulmonares encontramos sibilancias respiratorias diseminadas en ambos hemitórax, no se integra un síndrome pleuropulmonar y no hay otros ruidos agregados.

Por lo tanto, la primera pregunta es: ¿qué diagnóstico integraremos en este paciente? La paciente tiene fiebre, datos de dificultad respiratoria; lo primero que tenemos que conocer es que la definición operacional de enfermedad viral respiratoria se cumple en este paciente, cuando hacemos una integración diagnóstica y hacemos un diagnóstico nosológico por los antecedentes familiares, por la edad del niño, por la presentación clínica podríamos hablar que el niño tiene una infección respiratoria de vía inferior y que por la edad y las sibilancias se trata de un cuadro de bronquiolitis. Estos casos en la mayor proporción se deben al virus sincicial respiratorio. El médico que no tenga la experiencia clínica en estos casos podría diagnosticar este caso como COVID-19.

¿Este caso clínico se puede manejar de manera ambulatoria? No, este paciente tiene al menos cuatro criterios de gravedad, por lo tanto, en el momento que ya lo estamos revisando y estamos detectando estos datos de alarma se tiene que hacer la referencia a un Segundo Nivel de atención, y así se beneficie por el tratamiento en una terapia intensiva o en un servicio de pediatría.

En estos casos, ¿cuáles son los datos de alarma que deben vigilar los familiares? Esencialmente, los datos de dificultad respiratoria, la presencia de polipnea, rechazo al alimento, aumento del trabajo respiratorio, letargo o convulsiones. Tener en cuenta que nuestro caso clínico ya tiene varios de estos datos, por lo tanto, el caso no se debe manejar en un Primer Nivel. Se debe orientar al familiar para que el niño llegue a un hospital de Segundo o Tercer Nivel para atenderse oportunamente y evitar al máximo la presentación de complicaciones.

Para concluir, debe mencionarse que el médico de primer contacto debe enfocarse en promover la salud y esta pandemia nos ha ayudado a ver cuáles son nuestras debilidades como población 
para presentar con mayor gravedad COVID-19. Debemos detectar oportunamente las enfermedades y garantizar su atención integral y su referencia oportuna, en el contexto de COVID-19, la evaluación clínica es fundamental para que nosotros podamos categorizar un paciente adecuadamente y que se utilicen de una manera ineficiente los recursos que tenemos.

Podemos encontrar un paciente que cumpla con la definición de COVID-19 leve y manejarlo en el Primer Nivel de atención, sin necesidad de agotar los recursos de un Segundo o de un Tercer Nivel, los datos de alarma son los que deben dictaminar la referencia oportuna a un Segundo Nivel de atención y, por último, muchas de las comorbilidades asociadas con COVID-19, sobre todo la población pediátrica tienen su origen en la falta de la promoción de la salud y de los hábitos saludables de la población, por lo tanto, tenemos un compromiso muy importante como médicos de primer contacto para disminuir la presentación de estas comorbilidades en una edad adulta y que a su vez pudieran proteger a nuestros niños de enfermedades con mayor gravedad.

\section{AGRADECIMIENTOS}

Agradecimiento a la alumna pasante de servicio social Enf. Dellaneyra Gutiérrez Santiago de la licenciatura de Enfermería por su colaboración en la transcripción del texto.

\section{LECTURAS RECOMENDADAS}

1. Control y seguimiento de la nutrición, el crecimiento y desarrollo de la niña y del niño menor de 5 años. México: Secretaría de Salud; 2 de diciembre de 2015.

2. Comunicado oficial. Dirección General de Epidemiología. Secretaría de Salud. Agosto 24, 2020.

3. COVID-19 Treatment Guidelines Panel. Coronavirus Disease 2019 (COVID-19) Treatment Cuidelines.
National Institutes of Health. Available at https://www. covid79treatmentguidelines.nih.gov/.

4. Davies CJ,Waters D. Asystematic review of the psychometric properties of bronchiolitis assessment tools. J Adv Nurs. 2017; 73 (3): 286-301. doi: https://doi.org/10.1111/jan.13098.

5. De Souza TH, Nadal JA, Nogueira RJ, Pereira RM, Brandao MB. Clinical manifestations of children with COVID-19: a systematic review. Pediatric Pulmonology. 2020; 1-8. doi: 10.1002/ppul.24885.

6. Götzinger F, Santiago-García B, Noguera-Julián A, Lanaspa M, Lancella L, Calò Carducci FI. COVID-19 in children and adolescents in Europe: a multinational, multicentre cohort study. Lancet Child Adolesc Health. 2020; 9 (4): 647-708. Available in: https://doi.org/10.1016/S2352-4642(20)30177-2.

7. Jiang L, Tang K, Levin M, Irfan O, Morris SK, Wilson K et al. COVID-19 and multisystem inflammatory syndrome in children and adolescents. Lancet Infect Dis. 2020; 20 (11): E276-E288. https://doi.org/10.1016/S1473-3099(20)30651-4.

8. Jones VG, Mills M, Suarez D, Hogan CA, Yeh D, Bradley SJ et al. COVID-19 and Kawasaki disease: novel virus and novel case. hospital pediatrics. 2020; 10 (6): 537. doi: https://doi. org/10.1542/hpeds.2020-0123.

9. Liguoro I, Pilotto C, Bonanni M, Ferrari M, Pusiol A, Nocerino A et al. SARS-COV-2 infection in children and newborns: a systematic review. Eur J Pediatr. 2020; 1-18. doi: https://doi. org/10.1007/s00431-020-03684-7.

10. Ludvigsson J. Children are unlikely to be the main drivers of the COVID-19 pandemic-A systematic review. Acta Paediatrica. 2020; 109: 1525-1530. doi: 10.1171/apa.15371.

11. Abrams JY, Godfred-Cato SE, Oster ME, Chow EJ, Koumans $\mathrm{EH}$, Bryant B et al. Multisystem inflammatory syndrome in children (MIS-C) Associated with SARS-CoV-2: a systematic review. J Pediatr. 2020; 226: 45-54. doi: https:// doi.org/10.1016/j.jpeds.2020.08.003.

12. Mustafa NM, Selim LA. Characterisation of COVID-19 pandemic in paediatric age group: a systematic review and meta-analysis. J Clin Virol. 2020; 128: 1-9. doi: 10.1016/j. jcv.2020.104395.

13. Chang T, Wu JL, Chang LY. Clinical characteristics and diagnostic challenges of pediatric COVID-19: a systematic review and meta-analysis. J Formos Med Assoc. 2020; 119: 982-989. doi: https://doi.org/10.1016/j.jfma.2020.04.007.

14. Yasuhara J, Kuno T, Takagi H, Sumitomo N. Clinical characteristics of COVID-19 in children: a systematic review. Pediatric Pulmonology. 2020; 1-11. doi: 10.1002/ppul.24991. 